\title{
ANÁLISE FITOQUÍMICA E ATIVIDADE ANTIFÚNGICA DO EXTRATO ETANÓLICO DO RESÍDUO DE FOLHAS E MADEIRA DE MACACAPORANGA
}

\author{
Katiane Araújo Lourido'; Bruna Cristine Martins de Sousa²; Lauro Euclides Soares Barata3; \\ Denise Castro Lustosa ${ }^{4}$.
}

\footnotetext{
${ }^{1}$ Universidade Federal do Sul e Sudeste do Pará, Santarém, Pará, Brasil, katialourido@gmail.com 2 Universidade Federal do Sul e Sudeste do Pará, Santarém, Pará, Brasil, bruna0909martins@hotmail.com ${ }^{3}$ Universidade Federal do Sul e Sudeste do Pará, Santarém, Pará, Brasil, lauroesbarata@gmail.com

${ }^{4}$ Universidade Federal do Sul e Sudeste do Pará, Santarém, Pará, Brasil, denise.lustosa@ufopa.edu.br
}

RESUMO: Os óleos e extratos vegetais têm se destacado como alternativa promissora para o controle de fitopatógenos e, os resíduos sólidos provenientes da hidrodestilação de óleos essenciais também podem ser testados visando a obtenção de moléculas bioativas para esse fim. Objetivou-se avaliar a atividade antifúngica do extrato etanólico residual das folhas e madeira de Aniba parviflora (Meins.) Mez (macacaporanga) sobre o fungo Alternaria sp. provenientes de folhas de eucalipto. Os extratos foram obtidos via Soxhlet, após a extração do óleo essencial, e realizada a triagem fitoquímica através de cromatografia em camada delgada (CCD). No ensaio biológico, os extratos foram testados nas concentrações de 10\%, 20\%, 30\%, 40\% e 50\%, sendo solubilizados em água, adicionados em meio batata-dextrose-água (BDA) e vertidos para placas de Petri. Após solidificação do meio, depositou-se, centralmente, um disco de BDA contendo as estruturas do fungo. O tratamento controle consistiu da deposição de Alternaria em BDA, sem a presença dos extratos. Avaliou-se, diariamente, medindo-se o diâmetro médio das colônias, calculando-se a porcentagem de inibição do crescimento (PIC). $O$ delineamento foi inteiramente casualizado, em esquema fatorial, com quatro repetições. Verificou-se a presença de terpenóides e flavonoides nos extratos das folhas e madeira. O extrato da madeira e das folhas proporcionaram PIC de 30,3\% e de 21,4\%, respectivamente. As concentrações de $40 \%$ e $50 \%$ ocasionaram as maiores reduções no crescimento do fungo. Ambos os extratos apresentaram efeito fungistático nas concentrações testadas, sendo o da madeira mais promissor na redução do crescimento micelial do fungo.

PALAVRAS-CHAVE: Borra vegetal, Controle alternativo, Fungo.

\section{PHYTOCHEMICAL ANALYSIS AND ANTIFUNGAL ACTIVITY OF ETHANOLIC EXTRACT FROM LEAVES AND MACACAPORANGA WOOD RESIDUE}

ABSTRACT: Plant oils and extracts have emerged as a promising alternative for the control of phytopathogens, and the solid residue from the hydrodistillation of 
essential oils can also be tested in order to obtain bioactive molecules for this purpose. The objective of the study was evaluate the antifungal activity of the residual ethanolic extract of leaves and macacaporanga wood on the fungus Alternaria sp. from eucalyptus leaves. The extracts were obtained by Soxhlet, after extraction of the essential oil, and the phytochemical screening was performed by thin layer chromatography. In the biological assay, the extracts were tested at the concentrations of $10 \%, 20 \%, 30 \%, 40 \%$ and $50 \%$, being solubilized in water, added in potato-dextrose-water (PDA) medium and poured into Petri dishes. After solidification of the medium, a PDA disc containing the structures of the fungus was deposited centrally. The control treatment consisted of the deposition of Alternaria in PDA, without the presence of extracts. The mean diameter of the colonies was measured daily by calculating the percentage of growth inhibition. The design was completely randomized, in a factorial scheme, with four replications. The presence of terpenoids and flavonoids in leaves and wood extracts was verified. The extract of the wood and leaves provided ICPs of $30.3 \%$ and $21.4 \%$, respectively. Concentrations of $40 \%$ and $50 \%$ caused the greatest reductions in fungus growth. Both extracts presented a fungistatic effect in the tested concentrations, being the one of the wood more promising in the reduction of the mycelial growth of the fungus.

KEYWORDS: Alternative control, Fungus, Vegetable waste.

\section{ANÁLISIS FITOQUÍMICO Y ACTIVIDAD ANTIFÚNGICA DEL EXTRACTO ETANÓLICO DEL RESIDUO DE HOJAS Y MADERA DE MACACAPORANGA}

RESUMEN: Los aceites y extractos vegetales se han destacada como una alternativa prometedora para el control de fitopatógenos y los residuos sólidos provenientes de la hidrodestilación de aceites esenciales también pueden ser probados para la obtención de moléculas bioactivas para ese fin. Se objetivó evaluar la actividad antifúngica del extracto etanólico residual de las hojas y madera de Aniba parviflora (Meins.) Mez (macacaporanga) sobre el hongo Alternaria sp. provenientes de hojas de eucalipto. Los extractos fueron obtenidos vía Soxhlet, después de la extracción del aceite esencial, y realizada la clasificación fitoquímica a través de cromatografía en capa delgada (CCD). En el ensayo biológico, los extractos se probaron en las concentraciones del 10\%, 20\%, 30\%, 40\% y 50\%, siendo solubilizados en agua, añadidos en medio patata-dextrosa-agua (PDA) y vertidos para placas de Petri. Después de la solidificación del medio, se depositó, centralmente, un disco de PDA conteniendo las estructuras del hongo. El tratamiento control consistió de la deposición de Alternaria en BDA, sin la presencia de los extractos. Se evaluó, diariamente, midiendo el diámetro medio de las colonias, calculándose el porcentaje de inhibición del crecimiento (PIC). El delineamiento fue completamente casualizado, 
en esquema factorial, con cuatro repeticiones. Se verificó la presencia de terpeloides y flavonoides en los extractos de las hojas y la madera. El extracto de la madera y de las hojas proporcionó PIC del 30,3\% y del 21,4\%, respectivamente. Las concentraciones de $40 \%$ y $50 \%$ ocasionaron las mayores reducciones en el crecimiento del hongo. Ambos extractos presentaron efecto fungistático en las concentraciones probadas, siendo el de la madera más prometedor en la reducción del crecimiento micelial del hongo.

PALABRAS CLAVE: Control alternativo, Gomas vegetales, Hongo.

O controle de doenças em plantas, em geral, é realizado por meio da utilização de defensivos químicos, produtos estes que estão associados a contaminação ambiental e prejuízos a qualidade e expectativa de vida da população (FONSECA et al., 2015). Nesse sentido, estudos destacam a atividade biológica dos compostos de óleos essenciais e extratos vegetais como promissora alternativa ao controle de doenças em plantas (SCHWAN-ESTRADA, 2009; SOUSA et al., 2012; TOFFANO et al., 2012).

Os produtos provenientes de plantas medicinais ou aromáticas caracterizam-se por serem menos prejudiciais ao meio ambiente e eficientes no manejo de doenças (GARCIA et al., 2012). Possuem em sua composição química diversas substâncias com potencial fungistático ou fungicida que podem ser utilizadas diretamente pelo produtor ou servir de matéria-prima para a síntese de novos produtos (CELOTO et al., 2008).

Diversas plantas têm se destacado devido as suas propriedades terapêuticas, dentre elas Aniba parviflora (Meins.) Mez, conhecida popularmente como macacaporanga. É uma espécie aromática de médio porte, nativa da região amazônica e produtora de óleo essencial (FLORA DO BRASL, 2016; PEREIRA, 2012).

O óleo essencial desta espécie é caracterizado por um aroma forte e agradável, de coloração amarela e cheiro amadeirado (PEREIRA, 2012; PAREDES et al., 2014) e possui 
comprovada ação antimicrobiana a bactérias patogênicas aos humanos (VIANA et al., 2013).

Além dos óleos essenciais e dos extratos brutos, o resíduo sólido (borra) resultante da extração do óleo essencial é um produto pouco estudado para a obtenção de moléculas bioativas. Em geral, esse produto é descartado no meio ambiente ou reutilizado pela própria empresa de extração de óleo essencial no abastecimento de lareiras, para gerar energia (FISCHBORN, 2013).

Os resíduos obtidos da extração de óleos essenciais vêm sendo avaliados no controle de fitopatógenos pelo grupo de Pesquisa e Desenvolvimento de Produtos Naturais Bioativos P\&DBio, da Universidade Federal do Oeste do Pará, Santarém, PA. Nesse contexto, o trabalho objetivou avaliar a composição química e a atividade antifúngica, in vitro, de extratos etanólicos residuais das folhas e madeira de macacaporanga sobre o fungo Alternaria sp. proveniente de eucalipto (Eucalyptus spp.).
Foram coletadas folhas e madeiras de macacaporanga (Aniba parviflora (Meins.) Mez) de uma árvore com aproximadamente 15 anos de idade na área da fazenda Curauá $\left(-57^{\circ} 27^{\prime} 09^{\prime \prime} \mathrm{W}\right.$ e 02³4'23"S), comunidade de Jacamim, em Santarém, Pará. As folhas foram coletadas de galhos da extremidade e a madeira consistiu dos ramos principais ligados ao troco, a casca foi retirada para a extração.

processo de extração e triagem fitoquímica foi realizado no Laboratório de Pesquisa e Desenvolvimento de Produtos Naturais Bioativos (P\&DBio), do Instituto de Biodiversidade e Floresta - Ibef, da Universidade Federal do Oeste do Pará - Ufopa.

Após a extração do óleo essencial por hidrodestilação, os resíduos (borra) das folhas e madeira resultantes foram usados para a obtenção dos extratos em aparelho Soxhlet, por um período de oito horas, utilizando-se $45 \mathrm{~g}$ dos resíduos secos e como solvente o etanol 96\%.

Os rendimentos dos extratos obtidos dos resíduos foram calculados 
segundo Taube Júnior et al. (2013), sendo de $10,4 \%$ para o extrato das folhas e 5,5\% para extratos dos galhos.

A triagem fitoquímica dos extratos dos resíduos foi realizada por meio de Cromatografia em Camada Delgada (CCD), somente para as classes dos terpenos e flavonóides, conforme metodologia adaptada de Taube Jr. et al. (2013), na qual pesou-se 10mg de cada extrato, que foram diluídos em $1 \mathrm{~mL}$ de metanol para a aplicação nas placas cromatográficas. O sistema testado foi hexano: acetato de etila (1:1) em placas cromatográficas de alumínio (10 x 10 cm) com fluorescência, de sílica gel 60 da marca Macherey-Nagel.. Para os terpenos o revelador utilizado foi a vanilina sulfúrica e para flavonóides o revelador foi a cloreto férrico.

O ensaio biológico foi conduzido no Laboratório de Fitopatologia Ibef/UFOPA. Os extratos foram testados nas concentrações de 10\%, 20\%, 30\%, 40\% e 50\% sobre o fungo Alternaria sp. isolado de Eucalipto (Eucalyptus spp.).
Para a obtenção das concentrações, os extratos residuais das folhas e madeira foram solubilizados em água, na proporção de 1:1, adicionados em meio batata-dextrose-ágar (BDA) e vertidos em placas de Petri. Após solidificação do meio, depositou-se, centralmente, um disco de meio $(0,4$ $\mathrm{mm}$ ) contendo as estruturas do fitopatógeno. O tratamento controle consistiu do cultivo do fungo em meio BDA, sem a presença dos extratos. O delineamento experimental foi inteiramente casualisado (DIC), em esquema fatorial $(2 \times 5)$, com quatro repetições. Avaliou-se o efeito fungitóxico dos extratos residuais medindo-se, diariamente, o diâmetro médio das colônias do fungo, durante sete dias. Ao final das medições, determinou-se o percentual de inibição do crescimento (PIC), segundo Sousa et al. (2013).

Os dados obtidos foram analisados pelo software estatístico Assistat $^{\circledR}$ versão 7.7 Beta e as médias comparadas pelo teste de Tukey a 5\% de probabilidade. 
De acordo com a CCD, verificou-se para os extratos residuais das folhas e madeira de macacaporanga, a presença das classes de compostos terpenóides e flavonoides. Paredes et al. (2014) realizando triagem fitoquímica com o extrato etanólico bruto das folhas e galhos finos da mesma espécie, observou a presença de flavonóides, taninos e saponinas para ambos os extratos.

No ensaio biológico houve diferença significativa para todos os fatores isoladamente (extratos residuais e concentrações), bem como para a interação entre eles $(p<0,01)$.

Para o fator extratos residuais das folhas e madeira, o extrato da madeira ocasionou maior redução no crescimento micelial do fungo, do que o extrato das folhas, sendo o PIC de $30,3 \%$ e 21,4\%, respectivamente. A ação dos extratos está relacionada as classes de compostos verificadas, terpenóides, taninos e flavonóides são metabólitos ativos com relatada ação antifúngica (ARIF et al., 2011, SALAS et al., 2011; SERPA et al., 2012).
Todas as concentrações avaliadas reduziram o crescimento micelial de Alternaria, em relação ao tratamento controle. As concentrações de 40\% e $50 \%$ proporcionaram os maiores PIC, não diferindo entre si (Figura 1). Pedroso et al. (2009) avaliando extratos de arruda (Ruta graveolens), louro (Laurus sp.), alho (Allium sativum) e manjericão (Ocimum basilicum) nas concentrações de 10\%, 20\% e 30\% sobre Alternaria solani, também observaram resultados promissores a partir da menor concentração testada.

Em relação a interação extratos residuais $x$ concentrações, observou-se diferença entre os extratos nas concentrações de 30\%, 40\% e 50\%, sendo as maiores porcentagens de inibição do crescimento de Alternaria sp. proporcionadas pelos extratos residuais da madeira (Tabela 1; Figuras 2 e 3). 
Figura 1. Percentual de inibição do crescimento (PIC) de Alternaria sp. submetidas a diferentes concentrações dos extratos residuais de macacaporanga. Médias seguidas pelas mesmas letras nas colunas não diferem entre si pelo teste de Tukey $(p \leq 0,05)$.

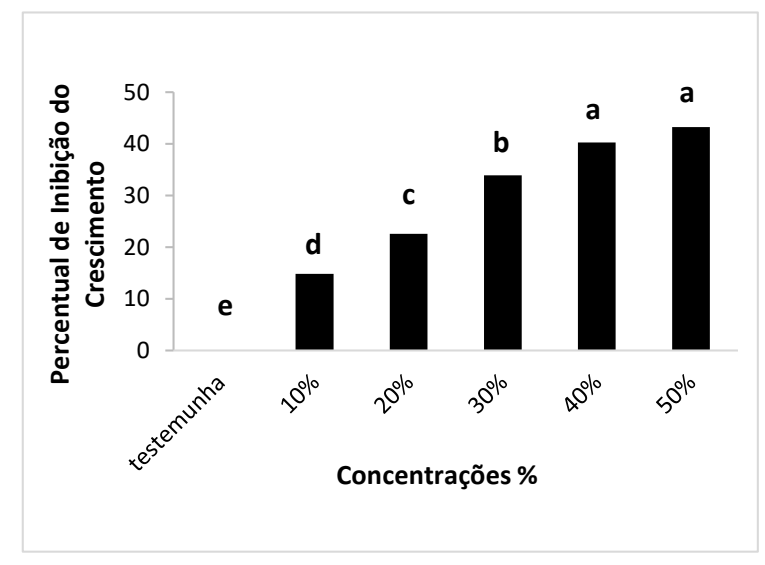

Tabela 1. Percentual de inibição de crescimento (PIC) do fungo Alternaria sp. submetido a diferentes concentrações dos extratos residuais de $A$, aos sete dias de crescimento.

\begin{tabular}{lcccccc}
\hline & \multicolumn{6}{c}{ Percentual de Inibição do Crescimento (PIC) } \\
\cline { 2 - 7 } Extratos & \multicolumn{6}{c}{ Concentrações dos Extratos Residuais (\%) } \\
\cline { 2 - 7 } Residuais & Controle & $10 \%$ & $20 \%$ & $30 \%$ & $40 \%$ & $50 \%$ \\
\hline Folha & $0,0 \mathrm{aE}$ & $13,7 \mathrm{aD}$ & $23,1 \mathrm{aD}$ & $25,0 \mathrm{bBC}$ & $31,6 \mathrm{bAB}$ & $35,3 \mathrm{bA}$ \\
Madeira & $0,0 \mathrm{aD}$ & $16,0 \mathrm{aC}$ & $22,1 \mathrm{aC}$ & $42,9 \mathrm{aB}$ & $49,1 \mathrm{aAB}$ & $51,4 \mathrm{aA}$ \\
\hline CV (\%) & & \multicolumn{7}{c}{} & & & 13,8 \\
\hline
\end{tabular}

Médias seguidas pelas mesmas letras minúsculas nas colunas e pelas mesmas letras maiúsculas nas linhas, não diferem entre si pelo teste de Tukey $(p \leq 0,05)$.

Sousa et al. (2013) testando extrato etanólico bruto das folhas de macacaporanga e cumaru sobre fungos do gênero Fusarium spp. isolado de espécies florestais, verificaram a ação fungitóxica do extrato de macacaporanga em todas as concentrações testadas (10\%, 20\%, $30 \%, 40 \%$ e $50 \%)$. 
Figura 2. Colônias do fungo Alternaria sp. (Eucalipto), submetidas às diferentes concentrações dos extratos residuais de folhas de Aniba Parviflora (macacaporanga).

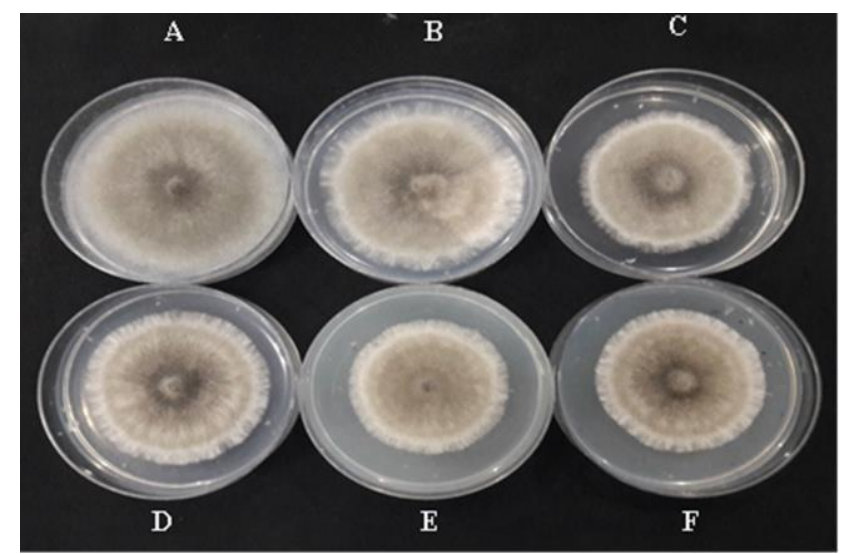

A. Colônia do fungo na ausência do extrato (controle); B. Fungo na presença do extrato na concentração de 10\%; C. Colônia do fungo na presença do extrato na concentração de 20\%; D. Colônia do fungo na presença do extrato na concentração de 30\%; E. Colônia do fungo na presença do extrato na concentração de $40 \%$ e F. Colônia do fungo na presença do extrato na concentração de 50\%.

Figura 3. Colônias do fungo Alternaria sp. (Eucalipto), submetidas às diferentes concentrações dos extratos residuais da madeira de Aniba Parviflora (macacaporanga).

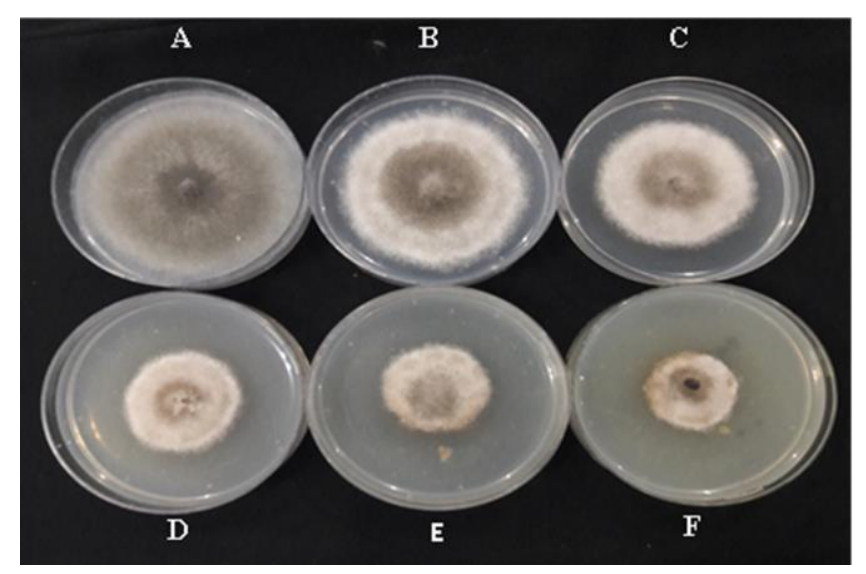

Onde: A. Colônia do fungo na ausência do extrato (controle); B. Colônia do fungo na concentração de 10\%; C. Colônia do fungo na concentração de 20\%; D. Colônia do fungo na concentração de 30\%; E. Colônia do fungo na concentração de $40 \%$ e F. Colônia do fungo na concentração de 50\%. 
Os extratos residuais das folhas e madeira apresentaram análise fitoqu semelhante. No entanto, os extratos da madeira proporcionaram maiores porcentagens de inibição do crescimento do fungo Alternaria sp., sendo a atividade antifúngica mais efetiva nas maiores concentrações.

\section{REFERÊNCIAS}

ARIF, T.; MANDAL, T. K.; DABUR, R. Natural products: Anti - fungal agents derived from plants. Opportunity. Challenge and Scope of Natural Products in Medicinal Chemistry, v. 81, p. 283 - 311, 2011.

CELOTO, M. I. B.; PAPA, M. F. S.; SACRAMENTO, L. V. S.; CELOTO, F. J. Atividade antifúngica de extratos de plantas a Colletotrichum gloeosporioides. Acta Scientiarum Agronomy, Maringá, v. 30, n.1, p. 1-5, 2008.

FISCHBORN, A.C. Aproveitamento do resíduo sólido da hidrodestilação de Aniba parviflora (Meissn) Mez E Aniba rosaeodora Ducke (Lauraceae): Obtenção de enzimas fúngicas. Dissertação de mestrado. Biotecnologia e recursos naturais da Amazônia. Universidade do Estado do Amazonas (UEA), Manaus, AM, 2013.

FLORA DA BRASIL. Flora do Brasil 2020 em construção. 2016. Jardim
Botânico do Rio de Janeiro. Disponível em:

<http://floradobrasil.jbri.gov.br/reflora /floradobrasil/FB23350>. Acesso em: 04/12/16.

FONSECA, M. C. M.; LEHNER, M. S.; GONÇALVES, M. G.; PAULA JÚNIOR, T. J.; SILVA, A. F.; BONFIM, F. P. G.; PRADO, A. L. Potencial de óleos essenciais de plantas medicinais no controle de fitopatógenos. Revista Brasileira de Plantas Medicinais, Campinas, v. 17, n. 1, p. 45-50, 2015.

GARCIA, R. A.; JULIATTI, F.C.; BARBOSA, K. A. G.; CASSEMIRO, T. A. Atividade antifúngica de óleo e extratos vegetais sobre Sclerotinia sclerotiorum. Bioscience Journal. v. 28, n. 1, p. 48-57, 2012.

PAREDES, S. A. H.; BATISTA, L. T.; DUVOISIN, Jr. S.; ALBUQUERQUE, P. M. Estudo Fitoquímico de Aniba parviflora e seu Potencial Antioxidante. In: Congresso Brasileiro de Engenharia Química, 20., 2014. Anais ... Florianópolis - Sc. 2014.

PEDROSO, D. C.; JUNGES, E.; MENEZES, V.; MULLER, J.; GIRARDI, L. B.; TUNES, L. M.; MUNIZ, M. F. B.; DILL, A. Crescimento micelial de Alternaria solani na presença de extratos vegetais. Revista Brasileira de Agroecologia, v. 4, n. 2, nov. 2009.

PEREIRA, I. C. Fitoquímica, biometria e germinação de Aniba fragans (macacaporanga) cultivadas no município de Santarém. Dissertação de mestrado. Programa de pós- 
graduação em Recursos Naturais da Amazônia. Universidade Federal do Oeste do Pará. 2012.

SALAS, P. M.; CÉLIZ, G.; GERONAZZO, H.; DAZ, M.; RESNIK, S. L. Antifungal activity and enzymatically - modified flavonoids isolated from citrus species. Food Chemistry, v. 124, p. 1411-1415, 2011.

SCHWAN-ESTRADA, K. R. F. Extratos vegetais e de cogumelos no controle de doenças de plantas. Horticultura Brasileira, Vitória da Conquista, v. 27, n. 2, p. 4038-4045, 2009. Suplemento - CD-ROM.

SERPA， R.; FRANÇA， E.; MAIA， L.; ANDRADE, C.; DINIZ, A.; FURLANETO, M. In vitro antifungal activity of the flavonoid baicalein against Candida species. Journal of Medical Microbiology, v. 61, p. 1704 - 1709, 2012.

SOUSA, B. C. M.; LUSTOSA, D. C.; LIMA, A. C. E.; BARATA, L. E. S.; CASTRO, K. C. F. Avaliação in vitro de extratos de cumaru e macacaporanga sobre fungos de espécies florestais da Amazônia. In: SIMPÓSIO BRASILEIRO DE ÓlEOS ESSENCIAIS,7., 2013. Livro de Resumos... Santarém, Pará: UFOPA, 2013.

SOUSA, R. M. S.; SERRA, I. M. R. S.; MELO, T. A. Efeito de óleos essenciais como alternativa no controle de Colletotrichum gloeosporioides, em pimenta. Summa Phytopathol. V. 38, n. 1, p. 42-47, 2012.
TAUBE JÚNIOR, P.; CASTRO, K. C. F.; BARATA, L. E. S. Experimentos de Química. Santarém: UFOPA, 2014. 242 p.

TOFFANO, L.; FISCHER, I. H.; BLUMER, S., PASCHOLATI, S. F. Potencial do flavedo (epicarpo) de Citrus aurantifolia cv. Tahiti no controle do bolor verde e da antracnose em citros. Summa Phytopathol. v. 38, n. 1, p. 6166, 2012.

VIANA, B. I. S.; GAZEL, C. L. L.; AMARAL, D. F.; SILVA, A. S.; BARATA, L. E. S.; ESCHER, S. K. S. Atividade antimicrobiana do óleo essencial de Aniba parviflora (macacaporanga) frente às cepas de interesse clínico. In: SIMPÓSIO BRASILEIRO DE ÓLEOS ESSENCIAIS,7., 2013. Livro de Resumos... Santarém, Pará: UFOPA, 2013. 